\title{
Novel retrieval basket for the extraction of choledocholithiasis
}

The management of choledocholithiasis can be a challenging problem depending on the number, size, and location of the stones. Therapeutic endoscopic retrograde cholangiopancreatography (ERCP) has been the standard of care for decades. Various tools and techniques have been used during ERCP including, but not limited to, sphincteroplasty, extraction balloon, mechanical lithotripsy with trapezoid basket, extracorporeal shockwave lithotripsy, and direct cholangioscopy with lithotripsy. Residual stones may remain even after adequate balloon sweeps and negative occlusion cholangiogram, especially if the bile duct is dilated and stones are small, escaping the balloon sweeps [1]. Direct cholangioscopy has proven to be a useful tool in directly visualizing the ducts for any residual stones in order to achieve complete clearance [2, 3].

The SpyGlass retrieval basket (Boston Scientific, Marlborough, Massachusetts, USA) is one of the new tools that can be used to extract stones found during cholangioscopy. We present a video case of choledocholithiasis in which the SpyGlass retrieval basket was used to extract the residual stones in the bile duct ( $\vee$ Video 1 ).

A 60-year-old woman with no significant medical problems was referred to us for intermittent right upper quadrant abdominal pain and multiple retained choledocholithiasis. She had no symptoms or signs of cholangitis. ERCP was performed. Initial cholangiogram showed a dilated bile duct with multiple small and large filling defects in most of the common bile duct and common hepatic duct, consistent with the presence of stones.

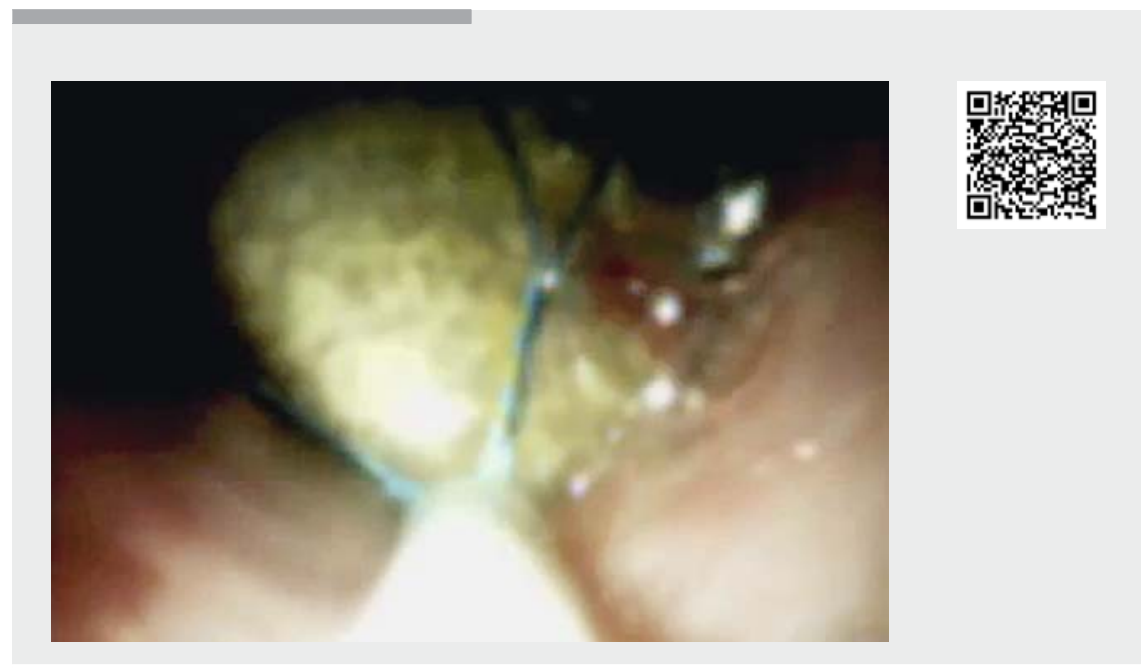

Video 1 Novel SpyGlass retrieval basket (Boston Scientific, Marlborough, Massachusetts, USA) for the retrieval of choledocholithiasis. Source for stent: Boston Scientific.

Sphincterotomy was performed and multiple large stones were extracted using a 12-mm extraction balloon catheter. As we suspected retained stones, SpyGlass cholangioscopy was performed, which showed one residual stone in the cystic duct and two residual stones in the left hepatic duct. A SpyGlass retrieval basket was then used and all the stones were extracted.

No adverse events were reported. The patient was discharged home in a stable condition.

Endoscopy_UCTN_Code_TTT_1AR_2AH FB

\section{Competing interests}

Nirav Thosani is Boston Scientific consultant.
The authors

Srinivas Ramireddy, Tomas R. DaVee, Ricardo Badillo, Nirav Thosani

Interventional Gastroenterologists of the University of Texas (iGUT), Department of Gastroenterology, Hepatology and Nutrition, Houston, Texas, United States

\section{Corresponding author}

Srinivas Ramireddy, MD

Interventional Gastroenterologists of the University of Texas (iGUT), Department of Gastroenterology, Hepatology and Nutrition, 6431 Fannin MSB 4.234, Houston, Texas 77030 , United States

Fax: +1-713-500-6699

rsr.vasu@gmail.com 


\section{References}

[1] Sejpal DV, Trindade AJ, Lee C et al. Digital cholangioscopy can detect residual biliary stones missed by occlusion cholangiogram in ERCP: a prospective tandem study. Endosc Int Open 2019; 7: E608 - E614

[2] Anderloni A, Auriemma F, Fugazza A et al. Direct peroral cholangioscopy in the management of difficult biliary stones: a new tool to confirm common bile duct clearance. Results of a preliminary study. J Gastrointestin Liver Dis 2019; 28: 89-94
[3] Brewer OI, Bekkali NLH, Raijman I et al. Efficacy and safety of digital single-operator cholangioscopy for difficult biliary stones. Clin Gastroenterol Hepatol 2018; 16: 918 926

\section{Bibliography}

DOI https://doi.org/10.1055/a-0987-9851

Published online: 21.8.2019

Endoscopy 2020; 52: E43-E44

(c) Georg Thieme Verlag KC

Stuttgart · New York

ISSN 0013-726X

\section{ENDOSCOPY E-VIDEOS}

https://eref.thieme.de/e-videos

回局 Endoscopy E-Videos is a free access online section, reporting 田: on interesting cases and new techniques in gastroenterological endoscopy. All papers include a high quality video and all contributions are freely accessible online.

This section has its own submission website at

https://mc.manuscriptcentral.com/e-videos 